\title{
Exploring the Value of Academic Librarians' Participation in Journal Clubs
}

\author{
Megan Fitzgibbons, Lorie Kloda, and Andrea Miller- \\ Nesbitt
}

\begin{abstract}
Journal clubs are meetings where participants engage in discussion or appraisal of professional literature and research. This study investigates the perceived value of librarians' participation in journal clubs. Using a hermeneutic dialectic process, we built a construction of the value of journal club participation based on interviews with academic librarians. In the construction, we demonstrate that librarians and their organizations benefit from the informal professional learning that takes place in journal clubs, by developing professional knowledge, building and strengthening communities of practice, increasing research capacity, and closing the research-to-practice gap.
\end{abstract}

\section{Introduction}

Ongoing professional development is essential for academic librarians to maintain their skills and remain effective in a changing academic landscape. Journal club participation is a cost-effective means for promoting ongoing development.

Sometimes referred to as "discussion groups" or "reading groups," we define journal clubs as meetings where participants engage in discussion or critical appraisal of research publications and other professional literature. The various purposes of journal clubs include developing a community of practice, learning about research trends and methodologies, and integrating evidence into practice. Journal clubs, therefore, can be linked to informal learning in the workplace.

Although several conceptualizations of informal learning exist, informal learning in the context of workplaces often refers to learning that occurs outside classrooms or training sessions but still involves some coordination and structure. Some examples of informal learning in the workplace include "lunch and learns," mentoring, on-the-job training and discussion groups. ${ }^{1}$ Informal learning in the workplace is often driven by the requirements of the job to improve skills and knowledge and thereby increase effectiveness in changing work environments. ${ }^{2}$ As such, organizations often encourage informal learning. ${ }^{3}$ One important characteristic of informal learning in the workplace is interaction between coworkers as part of the learning process. ${ }^{4}$ In keeping with these

Megan Fitzgibbons is Innovation Librarian at the University of Western Australia; e-mail: megan.fitzgibbons@gmail.com. Lorie Kloda is Associate University Librarian, Planning E Community Relations at Concordia University; e-mail: lorie.kloda@concordia.ca. Andrea Miller-Nesbitt is Liaison Librarian at McGill University; e-mail: andrea.miller-nesbitt@mcgill.ca. (2017 Megan Fitzgibbons, Lorie Kloda, and Andrea Miller-Nesbitt, Attribution-NonCommercial (http://creativecommons.org/licenses/by-nc/4.0/) CC BY-NC. 
definitions, journal clubs are structured activities that require group coordination, but they are not designed for learning in the way that training or classroom sessions are, with a set curriculum and instructors responsible for facilitating and assessing learning. In this way, journal clubs are communities that provide the motivation and opportunity necessary for informal learning to take place.

As the prevalence of journal clubs increases, ${ }^{5}$ it is important to understand their value to the academic library community. Inspired by the concept of informal learning, in this study we sought to gather empirical, qualitative evidence of the impact of journal club participation on librarians, building on previous investigations in this area. Although several publications have described librarians' involvement in journal clubs and methods for increasing their membership, there is no research to date demonstrating the potential impact of journal club participation.

This study seeks to address this issue by investigating: "What do librarians perceive as the value of participating in a journal club?" More specifically, the study explores:

- the perceived relevance of journal clubs for academic librarians;

- the perceived role of the journal club in facilitating a community of practice;

- the perceived impact of journal club participation on academic librarians' practice (that is, their use of evidence in practice);

- the perceived impact of journal club participation on academic librarians' research knowledge and skills; and

- $\quad$ other possible impacts identified by study participants.

\section{Literature Review}

Now popular in many professions, journal clubs are most common in the health sciences, as they were purportedly founded by physician Sir William Osler at McGill University in $1875 .{ }^{6}$ Similarly, although librarians in many sectors participate in journal clubs, they are most common among health sciences librarians, ${ }^{7}$ including one club dating back to at least $1976 .{ }^{8}$ Journal clubs often focus on critically appraising articles using pre-existing guidelines or tools. Critical appraisal tools, which are often based on the research methodology used, can facilitate analysis of the literature by providing an appropriate framework and therefore reduce uncertainty. ${ }^{9}$ These tools can allow participants to focus on central issues without overlooking important aspects of the article while assessing the validity, reliability, and applicability of the evidence presented. ${ }^{10}$ Journal clubs in any discipline can be seen as a tool for engaging in evidence-based practice. ${ }^{11}$ Lizaronda found that participants in a clinical journal club varied in their adoption of evidence-based thinking based on a variety of factors, but journal clubs seemed to have an impact on integrating evidence-based practice in their work. ${ }^{12}$

Kean explored the impact of librarians' involvement in online journal clubs for nurses and found that involvement increased awareness of the librarians' services and expertise. ${ }^{13}$ However, most previous studies about librarians and journal clubs focus on journal club participation in terms of librarians' own professional development.

Several publications have described the operation of journal clubs for librarians, including general reasons why the clubs were established and best practices for running them. ${ }^{14}$ A smaller number of studies have more closely investigated the outcomes and motivations behind librarians' involvement ${ }^{15}$ or the uptake of techniques, like using appraisal tools, in the context of journal clubs. ${ }^{16}$ These studies used surveys of participants in librarians' journal clubs to elicit information about their motivation for participating and the outcomes and therefore are limited in the depth to which they can explore participants' experiences.

The purpose of participating in journal clubs, according to these previous studies, can include: networking, personal growth, increasing awareness of library research 
and keeping up with the literature, the desire to practice and improve critical appraisal skills, promoting the value of professional scholarship, engaging in reflective practice and inspiring the application of research to practice. It has also been suggested that journal clubs are a low-cost option for professional development. ${ }^{17}$

In terms of best practices for journal clubs, Deenadayalan et al. ${ }^{18}$ used a systematic review approach to identify the following characteristics of effective journal clubs in clinical settings:

1. regular meetings

2. mandatory attendance for members

3. clear long- and short-term goals

4. appropriate meeting dates and incentives to attend

5. a trained journal club leader to lead discussion

6. circulating papers prior to the meeting

7. using the Internet for wider dissemination and data storage

8. using established critical appraisal methods and summarizing journal club findings.

These findings are in keeping with the good practices suggested in literature on librarians' journal clubs. ${ }^{19}$ Because potential impacts of journal clubs are dependent on the success of the initiative, in the present study we asked participants to describe characteristics of successful journal clubs as well as probing deeper into perceived impacts of participation.

\section{Methods}

The methodology employed for this study was the hermeneutic dialectic process, ${ }^{20}$ selected to develop a construction of the value of journal club participation based on participants' own experiences. This qualitative, interpretive method consisted of open-ended interviews with each study participant, followed by immediate analysis and formulation of a construction, or written document describing the interviewer's interpretation of the participant's experiences. The construction was subsequently revised after each new interview to incorporate the experiences of all participants. As such, the final construction was ultimately the result of analyzing and synthesizing all participants' data in an iterative manner. According to Guba and Lincoln, "[This process] is hermeneutic because it is interpretive in character, and dialectic because it represents a comparison and contrast of divergent views with a view to achieving a higher-level synthesis of them all." ${ }^{21}$ We chose this method to be able to explore participants' experiences in various contexts and to provide findings that include a wide variety, though not an exhaustive account, of these experiences. We believe this to be a novel use of the method in LIS research that may be relevant for similar types of exploratory investigations.

\section{Sampling and Recruitment}

The goal of this study was to develop a rich description of any of the possible outcomes of journal club participation, and we therefore used purposeful sampling. To be eligible to participate, potential study participants had to be English-speaking academic librarians who were current or recent participants in a journal club. Participation in a journal club was defined as attendance at two or more journal club meetings in the last 12 months. There were no restrictions by discipline of the journal club, region, or other criteria.

Before beginning recruitment, ethics approval was obtained from the institutional review boards of McGill University and the University of Western Australia. An invitation message was sent in August 2014 and again in September 2015 to 13 e-mail discussion lists aimed at academic librarians, covering a range of topics (information 
literacy, health librarianship, reference, assessment) and regions (United States, Canada, United Kingdom, Australia, and New Zealand). See appendix A for a list of mailing lists to which the invitation was sent. Existing journal clubs for librarians already known to the researchers, but not at their own institutions, were also contacted and the chairs or organizers distributed the recruitment message.

\section{Data Gathering and Building the Construction}

Written consent was obtained from all participants prior to interviews. All interviews took place using the voiceover Internet protocol (VoIP) software, Skype, and were recorded using an integrated application (CallNote). Each participant was interviewed by one of the three researchers, and the interviews lasted between 30 and 45 minutes. After each interview, all three researchers listened to the recorded interview, consulted notes from the interviewer and collaborated on building the written construction per Guba and Lincoln's method. Once all three researchers reached consensus on the construction, the next interview was scheduled. Because of the iterative nature of this method, during each interview the participant was exposed to themes from previous interviews, as described in the most recent version of the construction, and was invited to respond to them. The researchers continued to build the construction after each interview. This cycle continued until the construction appeared to take into consideration as many points of view as possible, allowing successive participants to refute or confirm the construction along the way.

The baseline interview guide, used for the interview with the first participant, is included in appendix B. The interview guide was revised and expanded after each interview based on the types of questions that emerged during the conversations. As we progressed through the interviews with participants and continued to build the construction, additional questions were added and some of the questions became more sophisticated.

Midway through the data collection, and once again after all interviews were completed, the construction was edited for clarity and shared with the participants via e-mail. We invited participants to comment on the construction, and in particular to let the researchers know if the construction did, or importantly, did not include their experiences. This step helped ensure that each participant's perspective was represented in the construction and the researchers' interpretation of the data was as accurate and inclusive as possible.

\section{Findings}

Twenty librarians from 18 different journal clubs participated in the study. Their positions and ranks varied from entry-level liaison librarians to experienced managers. Participants worked in libraries at universities in the United States $(n=9)$, Canada $(n=7)$, Australia $(\mathrm{n}=2)$, or New Zealand $(\mathrm{n}=2)$.

\section{Characteristics of Journal Clubs}

Of the participants, 15 were members in journal clubs for librarians and 5 were members of departmental journal clubs in the subject areas that they serve (such as bioinformatics, virology, oncology clinical guidelines group).

While there is some variation, it was found that journal clubs often have a set facilitator to select readings and guide the discussion and, in some cases, a distinct coordinator for logistical arrangements. These duties are frequently shared among club participants.

Journal clubs for librarians often discuss articles about librarianship in general or specific roles in librarianship, such as information literacy instruction or collection management. It is also common for topics to include the library environment and related fields, such as information technology or higher education. Research articles 
are the most common genre for journal club readings, but some groups also discuss trade publications, blogs, or video lectures.

In terms of logistics, journal clubs tend to meet on a regular basis with either a defined group of members or an open invitation. Journal clubs typically meet in person, but geographically dispersed groups use online chat and video conferencing tools such as Google Hangouts and Twitter.

\section{Perceived Impacts}

From iterative analysis of the data collected via the interviews, three major areas of impact emerged: 1) individual impacts; 2) group impacts; and 3) impacts on library users. The impacts presented in this section constitute a consensus among participants, with divergent views indicated when relevant.

\begin{tabular}{|c|c|c|}
\hline \multicolumn{3}{|c|}{$\begin{array}{c}\text { TABLE } 1 \\
\text { Summary of Impacts Identified }\end{array}$} \\
\hline Individual Impacts & Group Impacts & $\begin{array}{c}\text { Impacts on Library } \\
\text { Users }\end{array}$ \\
\hline $\begin{array}{ll}\text { - } & \text { Prioritizing time for } \\
\text { - } & \text { learning } \\
\text { - } & \text { Building knowledge } \\
& \text { Improving professional } \\
\text { skills } \\
\text { - } & \text { Building research skills, } \\
\text { including critical appraisal } \\
\text { Benefits from social } \\
\text { interaction }\end{array}$ & 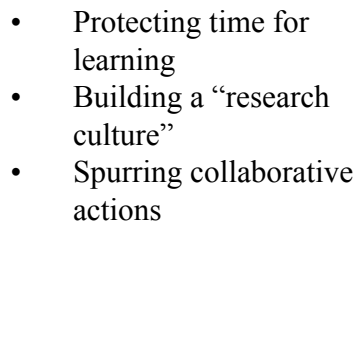 & $\begin{array}{l}\text { - } \\
\text { usew initiatives for } \\
\text { - Librarians are more } \\
\text { capable, which } \\
\text { benefits users }\end{array}$ \\
\hline
\end{tabular}

\section{Impacts on Individuals}

\section{Prioritizing time for learning and thinking}

This study found that journal clubs offer an opportunity for librarians to participate in professional development (sometimes earning continuing education credits) without the need to travel. This can be particularly helpful for librarians working toward recertification with their associations or other professional credentialing.

Many study participants described journal club as a means through which they can prioritize time for informal learning. The club format gives participants a greater sense of accountability in their reading, since they are expected to contribute to the group. One participant described journal club participation as a way to "build habits of professionalism and discipline" when engaging with professional literature.

Journal club participation also provides an opportunity and motivation for spending more in-depth, structured time on reading and discussion than would otherwise be possible in one's busy schedule. Many study participants described journal club as prompting reflection on their knowledge and work. Journal clubs can help expose participants to new ideas that they wouldn't otherwise have time to consider. Club meetings can also be an opportunity for facilitators to share their specialization or particular area of interest with other colleagues.

\section{Building knowledge}

All participants described gaining knowledge from participation in journal club, whether related to an academic discipline, research method, or trend in librarianship, especially in rapidly changing areas. Librarians may be able to use knowledge gained 
from journal clubs to provide guidance in decision making. Journal clubs also raise librarians' awareness of resources and tools that might be available to them. However, one participant noted that, for them, the purpose of journal club is not linked to keeping up with trends; rather, it's about looking at specific ideas in depth. Overall, participation in journal clubs seems to help librarians develop and integrate a corpus of knowledge that supports their work. It builds their knowledge, their confidence, and colleagues' and users' confidence in their professional expertise.

\section{Improving professional skills}

In some cases, participation in journal clubs was described as directly informing librarians' work. For example, study participants reported the following outcomes resulting from journal club discussions:

- Modifying information literacy instruction approaches and techniques

- Making decisions about offerings of services and resources

- Discovering new resources directly relevant to the community served

- Learning the terminology of a particular subject area

- Better connecting librarians' expertise and co-teaching duties with "ways of thinking" in their users' research disciplines

- Using articles as a foundation for informing project work.

One study participant stated that participation in journal club cannot be directly attributed with changes being made to practice because of other factors involved, particularly the organization's readiness to change. However, according to this participant, journal club can influence practice in a cumulative way and may affect future decisions. The information from journal club discussions is integrated in participants' knowledge base, which they can draw from later. Similarly, sometimes changes have not yet been made following recent journal club discussions because more time is needed for implementation.

\section{Building research skills, including critical appraisal}

For participants whose jobs require or encourage research and publication, journal clubs are often connected to their research practice.

Several study participants described journal clubs as influencing the direction and design of their own research. Librarians intending to disseminate the results of their research in the form of posters, presentations, or publications recognize that their work may be scrutinized later by colleagues. Journal club discussions can help inform their selection of methods for research.

Indeed, for one journal club coordinator, the club's main goal is to offer a space that supports participants' development of research capacity, to inspire new areas of interest, to highlight where they can contribute, and to identify gaps in the professional literature.

Some participants described journal clubs as increasing their personal research capacity through focusing on how methods are constructed, how to conduct effective assessment, and what is needed for publication.

Finally, some study participants reported seeing journal clubs as presenting opportunities to learn how to critically appraise or evaluate methodology, which gives them credibility when teaching these skills to students or assisting researchers.

\section{Social benefits}

Some study participants reported feelings of satisfaction from the activity of organizing or participating in a journal club. For many, journal clubs are an opportunity to make social connections (for example, for new hires) for librarians who work solo, for those 
who work in large organizations with multiple branches/departments, for librarians interested in meeting colleagues at other institutions, and for librarians who attend departmental journal clubs. These librarians see journal clubs as an opportunity to develop relationships and cultivate a sense of belonging. Being together in the same space helps promote feelings of trust as well as awareness of others' interests and knowledge. This increased awareness of colleagues' work can be helpful for future interactions, especially in multi-institutional or cross-sectoral clubs.

For some study participants, journal clubs were reported to be a forum to raise issues of interest or concern to them by selecting a reading on the issue and directing the discussion. Several participants described their journal clubs as settings in which rank and status are "equalized" and therefore offer a "safe space" to discuss difficult issues. Journal clubs can provide an opportunity for participants to collectively reflect on their work and provide a nonjudgmental space that facilitates both heated debates and relaxed conversations. Nearly all journal clubs were reported to be collegial and welcoming, and some were depicted as a fun social environment in contrast to other structured group interactions.

\section{Impacts on the Journal Club Group and the Institution}

\section{Dedicating time for learning}

Many study participants described journal clubs as a way through which learning is given value within the organization. From one participant's perspective, the journal club is connected to other activities in the library, such as a librarywide discussion forum and a research support group, which also emphasize the importance of ongoing learning.

\section{Building a "research culture"}

Journal clubs can help promote an environment where scholarly activities are valued, often building communities of practice that extend beyond the scope of a single journal club meeting. Journal clubs can foster a culture of openness, dialogue, and debate with a scholarly focus. Some study participants stated that journal clubs help attendees feel supported in developing their research skills, which is important since research requirements for tenure were seen to be demanding in some institutions. Further, journal clubs can help participants feel that their own research activities are worthwhile.

Some participants stated that journal clubs have the potential to improve librarians' status as peers with the professoriate by enabling them to become collaborators in research and contributing to the institution's research output. Increasing familiarity with the research process (for example, grant applications) and various methodologies (such as systematic reviews) is similarly beneficial. According to some study participants, this in turn could lead to improved perception of the value of the library within the institution, increased use of library services, and potentially increased funding.

Some journal clubs keep track of articles discussed through blogs or databases. Study participants who reported this practice noted that they could then refer back to past meetings as needed to identify relevant evidence when a question or related situation arose. One group also analyzes their record of past readings to identify trends in their choices of topics, types of studies, and journals discussed to shed light on issues of importance to their club and to gain a coherent picture of the type of evidence that they use to inform their practice.

Some study participants thought that journal clubs could demonstrate to decision makers that there is an interest in research within the organization, which could result in additional support from the administration for research activities. Finally, an active journal club can demonstrate a library's commitment to evidence-based practice in general. 


\section{Spurring further collaborative actions}

Several study participants described collaborative initiatives or actions that resulted from journal clubs. Examples include changes to a team's teaching strategies, collaborations with other campus departments, or staff training sessions - all informed by journal club discussions. Departmental journal clubs also give librarians an opportunity to discuss mutual interests with faculty members and students that can lead to collaborations.

Journal clubs can help the group confirm that current services and practices are well founded, based on the success of similar practices elsewhere as reported in the literature. Journal club discussions can also allow participants to identify areas in their institution that would benefit from structured research/investigation.

Finally, journal clubs that extend beyond a single institution can help promote the potential benefits of journal clubs more widely and spark cross-institution collaboration.

\section{Impacts on Users}

\section{New initiatives for users}

Although this study does not evaluate claims that librarians' participation in journal club benefited library users, it is clear that some participants believe their practice has changed for the better as a result of readings or discussions in journal clubs. Nevertheless, most study participants did not readily find an example of impact on users that could be solely attributed to journal clubs. Study participants reported some initiatives resulting from journal clubs that had a positive impact on library users, including:

- changes to an information literacy instruction program;

- improvements to teaching effectiveness and engagement;

- embedding information literacy support materials into a learning management system;

- collecting more comprehensive information on individual consultations for assessment purposes;

- decision making about selecting a discovery tool;

- creation of office hours for a subject librarian to better serve students and staff in an academic department; and

- new workshops for users on library services and resources resulting from a departmental journal club.

\section{Librarians are more capable, which benefits users}

Since librarians engaged in professional development and informal learning improve their knowledge and skills (making them more effective professionals), many of the individual benefits on journal club participants described earlier can be extrapolated to having an indirect impact on library users. Study participants reported the following impacts on users tied to journal club participation:

- allowing librarians to engage with research in the way that other faculty do, which helps in understanding faculty members' work

- improving critical appraisal skills, crucial to teaching students how to critically appraise information

- $\quad$ more in-depth disciplinary knowledge, allowing librarians to better assist and collaborate with students and faculty

- $\quad$ providing librarians with more credibility among academic faculty.

In departmental journal clubs, librarians' participation reportedly raises visibility of librarians' roles, which can lead to more interactions, assistance given, and collaborations that otherwise would not have happened. Librarians who participate in departmental journal clubs can also make a direct contribution to the clubs' success as organizers and attendees. 


\section{Journal Club Success}

In addition to describing the impacts of participating in journal clubs, study participants also provided thoughts on what makes a journal club successful as well as potential achievements of journal club. According to participants, one key sign of a successful journal club meeting is that those in attendance learn something, or reflect on an issue, that they can apply to their work. Effective meetings were described as having balanced discussions that continue after the meeting has ended and leave participants feeling stimulated and inspired. Participants proactively bringing ideas and suggesting topics for discussion is another indication of success. Some study participants also described success as when participants learn methods that can be used to answer questions they come across in their professional work.

Many study participants expressed that journal club success requires persistent efforts over time on the part of coordinators to ensure that interest grows and participation increases. Study participants cited several factors related to logistics that contribute to success, such as providing refreshments or having the discussion at a mealtime; having a physical or virtual space conducive to group interaction; dedicated facilitators and a core group of attendees; and support from administrators or professional associations. It was also reported that journal clubs are successful when a variety of attendees from different branches, roles, or organizations were included and when attendees were interested in learning about new ways of doing things and open to exploration.

In terms of topics, journal clubs with a specific focus (such as medical librarianship or information literacy) seem to increase the chances that participants will have shared goals and be motivated to participate. Some journal clubs were also successful in tying their meeting topics to the themes specified in accreditation standards by professional associations.

Participants reported that running successful journal clubs can prove challenging, and some factors that were identified as potentially limiting the success of journal clubs include a lack of commitment and lack of participation outside a small group and, for virtual journal clubs, difficulties in scheduling across different time zones. Some participants saw it as detrimental when administrators used the journal club as a forum to push a particular agenda. A few study participants reported feeling uncomfortable with the negative tone of some journal club meetings when there was too much focus on finding points to criticize in the article discussed. While one participant thought that using critical appraisal tools might help with this problem, another participant reported that her group specifically decided to not use critical appraisal tools to keep the focus more on "what can we learn" rather than criticism. A final frustration mentioned by a few study participants was a lack of time at work to implement ideas that arose in journal club discussions.

\section{Discussion}

This study's unique use of a hermeneutic dialect process led to a synthesis of different viewpoints on the perceived impacts of librarians' participation in journal clubs, incorporating individual impacts, group impacts, and impacts on library users.

Study participants described their journal clubs as safe spaces where informal learning in the workplace (as defined by Marsick and Watkins) ${ }^{22}$ could flourish. They provide motivation for reading, reflection, and writing with the time and task sufficiently structured. The social benefits of journal clubs mentioned in previous studies ${ }^{23}$ were also reported among the present study's participants, who describe journal clubs as building positive, supportive, and fun communities in which learning can take place. The present study further identifies the types of learning that take place, namely knowledge about the practice of librarianship, research skills, and (in some cases) subject-specific knowledge. Group learning or socialization processes were also reported. 
Previous literature connects journal clubs to evidence-based practice. ${ }^{24}$ The present study contributes specific examples of how journal club participants realize this connection, as many reported using critical appraisal tools, aiming to develop research capacity, and incorporating studies discussed in their journal club in their decision-making processes or project work. The application of evidence-based practice is more effective when discussions and readings are recorded for later consultation (as also argued by Vilelle and Young). ${ }^{25}$ As found in Pearce-Smith's survey, journal club participation was reported to increase librarians' capacity for understanding and conducting research. ${ }^{26}$

Vilelle and Young's findings on organizational benefits of journal club participation were further expanded in the present study, offering concrete examples of how journal clubs can help to build a "research culture" and fuel further action within the organization. ${ }^{27}$

As indicated in previous surveys on the impacts of journal club participation, ${ }^{28}$ some respondents did not attribute journal club participation to changes in their practice or benefits for their users. However, other participants reported concrete changes in their thinking and specific initiatives that resulted from journal club participation. Moreover, study participants frequently described examples in which they felt that they had become more capable at their work as a result of participating in journal clubs, which potentially benefits their users.

In keeping with a systematic review on journal club success, ${ }^{29}$ participants in this study echoed many of the success factors and challenges mentioned in previous publications on journal clubs for librarians that relate to organizational planning and logistics. For example, having a variety of dedicated participants who share the facilitation work and convenient timing of meetings seem to be essential to success, ${ }^{30}$ while lack of time for participation is a significant barrier to sustaining the club. ${ }^{31}$

\section{Limitations}

There are limitations inherent in our study specifically, and in using the hermeneutic dialectic approach generally. In our study, the sample is limited because our recruitment e-mail was sent to specific e-mail lists and we required participants to be English-speaking librarians in academic settings. We received responses from Canada, Australia, New Zealand, and the United States. These findings are not intended to be representative of all librarians, or all academic librarians who have participated in journal clubs. In addition, participants reported only their own experience, which means that there is no corroborating evidence of their perceptions of the impact of participating in journal club. For example, this study does not include evaluations from managers or users about actual successes based on journal club activities.

Moreover, there are limitations to the hermeneutic dialectic approach. In building the construction, it is possible that researchers miss subtle nuances when interpreting the participants' experiences. Attempts are made to avoid this by practicing good interviewing techniques and by sharing a draft of the construction with participants and asking them to respond to it.

Finally, there are unavoidable decisions made by participants and researchers to include or exclude particular data or ideas based on people's different understandings of what is or is not important to communicate. Having three researchers independently analyze data from the interviews helped ensure that all relevant points were captured and that multiple interpretations were incorporated.

\section{Conclusion}

In the course of this study, we found that informal learning is a useful framework for understanding the value of journal club participation for academic librarians. Journal 
clubs provide value through three types of impact: individual impacts, group impacts, and impacts on library users. This suggests that journals clubs are an activity worth supporting in academic libraries and for academic librarians as a venue for professional development and community building.

Findings from this study have implications for those working in academic libraries as well as other library sectors. For librarians who belong to an existing journal club, this study provides support for the club's continuation and contribution to librarianship. This study also suggests some good practices and areas to consider related to assessing the value of journal clubs: for example, keeping track of discussions for future reference and analysis or connecting the club's activities to skill requirements for particular positions or for professional associations' credentialing.

For groups considering starting or restarting a journal club, several factors identified by study participants should be considered for a successful implementation. Chief among these is having dedicated leaders and participants to sustain the journal club's operations. Additionally, support from an organization or association is very helpful; but ultimately the participants, not managers, should drive the club.

For new librarians, the findings from this study suggest that journal clubs can have benefits on multiple levels, including building knowledge and professional capacity, as well as developing social connections and learning from others in an informal yet structured environment.

For midcareer librarians, journal clubs can be a space for developing reflective practice and promote continuous improvement. They can be an effective means of keeping current and learning about new areas of practice. Journal clubs can be an opportunity for more experienced librarians to share knowledge with newer colleagues. Participation in departmental or cross-institutional journal clubs can expand personal growth and forge new relationships.

Library managers can also derive these personal benefits by participating as a collegial member of a journal club. In addition, managers can have a role in supporting staff members' participation in a journal club (inside or outside the library) by affirming the club's potential to improve librarians' professional knowledge and skills. For directors and instructors in library and information studies programs or leaders of professional associations, it is important to note that journal clubs can be an effective forum for teaching critical appraisal skills and laying the foundation for continued engagement with research literature.

The hermeneutic dialectic process was suitable for this project because of its flexible, iterative approach and has potential for use in future LIS research. The process allowed us to collect a wide variety of perspectives, construct a picture of the impact of a specific activity (that is, journal club participation), and provide a model for continuously evaluating impact. The method also allowed us to purposefully select interviewees and engage with the participants as equals, with each experience considered in turn and incorporated in the construction.

This research builds on prior work and provides a more complete picture of the role of journal clubs for academic librarians. Questions remain, however, and future research in the area could explore the impact of journal clubs on library users more concretely. The present study population was restricted to academic librarians, and many of the participants were from health sciences libraries. A follow-up study with health sciences librarians from hospital and special library sectors would complement the findings. Another avenue for research is to explore the possibilities and existing successes of journals clubs as part of a framework for professional development and credentialing, as some study participants indicated that their club is already connected to credentialing activities. 
The opportunities for informal learning offered by participating in journal clubs provide academic librarians a means of ongoing professional development and thereby positively impact participants' skills and knowledge, promote evidence-based practice, and potentially improve services to users.

\section{Acknowledgements}

Preliminary findings from this study, including discussion of methodology, were presented verbally at the Qualitative and Quantitative Methods in Libraries International Conference, Paris, France, May 26-29, 2015, and at the Evidence-Based Library and Information Practice (EBLIP8) Conference, Brisbane, Australia, July 6-9, 2015. 


\section{APPENDIX A. E-mail Lists Used to Distribute Recruitment Message}

- Association of College and Research Libraries, University Libraries Section

- Australian Library and Information Association (ALIA Weekly)

- Canadian Health Libraries Association (CANMEDLIB-L)

- Canadian Library Association

- Chartered Institute of Library and Information Professionals, UK

- Instruction in Library Information (ILI-L)

- $\quad$ Library Assessment Discussion List (ARL-ASSESS)

- $\quad$ Library Reference Issues (LIBREF-L)

- Medical Library Association (MEDLIB-L)

- Medical Library Association Research Section (Research-MLA)

- Reference and User Services Association

- Special Libraries Association Academic Section

- Tertiary Libraries Special Interest Group (TelSIG) of the Library and Information Association of New Zealand Aotearoa

\section{APPENDIX B. Baseline Interview Guide}

[Introduction. Make sure recorder is functioning, and let participant know the conversation is being recorded. Ask if participant has any questions. Duration of the interview is expected to last no more than 1 hour, and participant can ask to stop at any time.]

1. How long have you worked as an academic librarian? How long at the current organization?

2. What is your position/role?

3. Why do you participate in journal club?

Prompt:

What do you get out of your participation in a journal club?

4. How has participating in the journal club made an impact?

Prompt:

I Impact on you, your knowledge, your practice, your work, your users, your decisions?

5. Are there expectations for librarians to conduct research/scholarship at your institution? If so, what are they?

6. Is there anything else about journal club participation that you want to discuss? Do you have any questions for me?

Conclusion: May we contact you with a summary of our findings later on to get your feedback?

\section{Possible additional questions:}

What would be your ideal journal club? (This could lead to responses about structure, content, or outcomes)

Prompts:

$\square \quad$ How would your ideal journal club be structured?

$\square \quad$ What content would your ideal journal club cover?

$\square \quad$ What kind of outcomes do you hope for in a journal club?

$\square \quad$ Do you use an appraisal tool to structure your journal club discussions?

$\square \quad$ Are staff who do not have professional qualifications as librarians invited to participate? 
Is there "official" administrative support or recognition of your journal club? Describe your journal club: how did it start, who attends, how often does it meet, how often do you attend, what do you do to prepare, how are articles selected, do you report meetings, how many people attend meetings, is there any follow-up?

Describe a typical meeting at your journal club.

\section{Notes}

1. Saul Carliner, "How Have Concepts of Informal Learning Developed over Time?" Performance Improvement 52, no. 3 (2013): 5-11.

2. Carliner, "How Have Concepts of Informal Learning Developed over Time?"; Megan A. Le Clus, "Informal Learning in the Workplace: A Review of the Literature," Australian Journal of Adult Learning 51, no. 2 (2011): 355-73.

3. Victoria J. Marsick and Karen E. Watkins, "Informal and Incidental Learning," New Directions for Adult and Continuing Education 2001, no. 89 (2001): 25-34.

4. Le Clus, "Informal Learning in the Workplace."

5. Philip Young and Luke Vilelle, "The Prevalence and Practices of Academic Library Journal Clubs," Journal of Academic Librarianship 37, no. 2 (2011): 130-36.

6. Maria J. Grant, "Journal Clubs for Continued Professional Development," Health Information E Libraries Journal 20, no. s1 (2003): 72-73; M. Linzer, "The Journal Club and Medical Education: Over One Hundred Years of Unrecorded History," Postgraduate Medical Journal 63, no. 740 (1987): 475-78.

7. Young and Vilelle, "The Prevalence and Practices of Academic Library Journal Clubs."

8. Richard S. Klein and Rose Slowinski, "Chicago Medical Library Journal Club," Bulletin of the Medical Library Association 64, no. 3 (1976): 320.

9. Andrew Booth and Anne Brice, Evidence-Based Practice for Information Professionals: A Handbook (London: Facet, 2004); Rachel Esson, "The Right Tools for the Job: A Usability Survey of Critical Appraisal Tools" (paper presented at the Library and Information Association of New Zealand (LIANZA) Conference, Rotorua, New Zealand, September 1, 2007).

10. Booth and Brice, Evidence-Based Practice for Information Professionals.

11. Esson, "The Right Tools for the Job"; Grant, "Journal Clubs for Continued Professional Development"; Nicola Pearce-Smith, "A Journal Club Is an Effective Tool for Assisting Librarians in the Practice of Evidence-Based Librarianship: A Case Study," Health Information E Libraries Journal 23, no. 1 (2006): 32-40.

12. Lucylynn M. Lizarondo, Saravana Kumar, and Karen Grimmer-Somers, "Exploring the Impact of a Structured Model of Journal Club in Allied Health: A Qualitative Study," Creative Education 3, no. 26 (2012): 1094-1100; Lucylynn M. Lizarondo et al., "Does Journal Club Membership Improve Research Evidence Uptake in Different Allied Health Disciplines: A Pre-Post Study," BMC Research Notes 5, no. 1 (2012): 588.

13. Emily B. Kean, "Assessment and Impact of a New Role as an Embedded Librarian in Nursing Online Journal Clubs," Journal of the Medical Library Association 101, no. 4 (2013): 335-38.

14. Eugene Barsky, "A Library Journal Club as a Tool for Current Awareness and Open Communication: University of British Columbia Case Study," Partnership: The Canadian Journal of Library and Information Practice and Research 4, no. 2 (2009); Liz Doney and Wendy Stanton, "Facilitating Evidence-Based Librarianship: A UK Experience," Health Information \& Libraries Journal 20 (2003): 76-78; Grant, "Journal Clubs for Continued Professional Development"; Theodore Hickman and Lisa Allen, "A Librarian's Journal Club: A Forum for Sharing Ideas and Experiences," College \& Research Libraries News 66, no. 9 (2005): 642-44; Denise Koufogiannakis, Marlene Dorgan, and Ellen Crumley, "Facilitating Evidence-Based Librarianship: A Canadian Experience," Health Information and Libraries Journal 20, no. s1 (2003): 73-75; Elizabeth W. Kraemer, "Keeping Up with Journals: A Library Journal Club at Oakland University," Journal of Academic Librarianship 33, no. 1 (2007): 136-37.

15. Pearce-Smith, "A Journal Club Is an Effective Tool," 32-40; Young and Vilelle, "The Prevalence and Practices of Academic Library Journal Clubs," 130-36.

16. Esson, "The Right Tools for the Job."

17. Dean Giustini, "Tipping Point(s): Informal Learning for Health Librarians in an Economic Downturn," Journal of the Canadian Health Libraries Association/Journal de l'Association des bibliothèques de la santé du Canada 30, no. 3 (2014): 113-16.

18. Y. Deenadayalan et al., "How to Run an Effective Journal Club: A Systematic Review," Journal of Evaluation in Clinical Practice 14, no. 5 (2008): 898.

19. Barsky, "A Library Journal Club as a Tool for Current Awareness and Open Communica- 
tion"; Doney and Stanton, "Facilitating Evidence-Based Librarianship"; Grant, "Journal Clubs for Continued Professional Development"; Koufogiannakis, Dorgan, and Crumley, "Facilitating Evidence-Based Librarianship."

20. Egon G. Guba and Yvonna S. Lincoln, "Construction and Reconstruction of Realities," in Fourth Generation Evaluation (Newbury Park, Calif.: Sage Publications, 1989), 142-55.

21. Ibid., 149.

22. Marsick and Watkins, "Informal and Incidental Learning," 25.

23. Barsky, "A Library Journal Club as a Tool for Current Awareness and Open Communication"; Hickman and Allen, "A Librarian's Journal Club a Forum for Sharing Ideas and Experiences"; Pearce-Smith, "A Journal Club Is an Effective Tool "; Young and Vilelle, "The Prevalence and Practices of Academic Library Journal Clubs."

24. Esson, "The Right Tools for the Job"; Grant, "Journal Clubs for Continued Professional Development"; Koufogiannakis, Dorgan, and Crumley, "Facilitating Evidence-Based Librarianship: A Canadian Experience"; Pearce-Smith, "A Journal Club Is an Effective Tool."

25. Young and Vilelle, "The Prevalence and Practices of Academic Library Journal Clubs."

26. Pearce-Smith, "A Journal Club Is an Effective Tool."

27. Young and Vilelle, "The Prevalence and Practices of Academic Library Journal Clubs."

28. Pearce-Smith, "A Journal Club Is an Effective Tool"; Young and Vilelle, "The Prevalence and Practices of Academic Library Journal Clubs."

29. Deenadayalan et al., "How to Run an Effective Journal Club," 898-911.

30. Barsky, "A Library Journal Club as a Tool for Current Awareness and Open Communication"; Doney and Stanton, "Facilitating Evidence-Based Librarianship"; Grant, "Journal Clubs for Continued Professional Development"; Hickman and Allen, "A Librarian's Journal Club"; Koufogiannakis, Dorgan, and Crumley, "Facilitating Evidence-Based Librarianship"; Kraemer, "Keeping Up with Journals"; Brenda L. Seago et al., "Journal Club with a Mission," Bulletin of the Medical Library Association 82, no. 1 (1994): 73-74; Young and Vilelle, "The Prevalence and Practices of Academic Library Journal Clubs."

31. Pearce-Smith, "A Journal Club Is an Effective Tool"; Young and Vilelle, "The Prevalence and Practices of Academic Library Journal Clubs." 